\title{
Studies of diamond-like carbon films prepared by ion beam-assisted deposition
}

\author{
HENG-DE LI and XIAO-MING HE \\ Department of Materials Science and Engineering. Tsinghua University, Beijing 100084, \\ People's Republic of China
}

\begin{abstract}
Ion beam-assisted deposition offers a novel and unique process to prepare diamond-like carbon (DLC) films at room temperature, with particularly good interface adhesion. This advantage was explored in this study to deposit highly wear-resistant coating on bearing 52100 steel. Both dual ion beam sputtering and ion beam deposition were employed. Various bombarding species and energy were investigated to optimize the process. Raman, X-ray photoelectron and Auger electron spectroscopy were used to characterize the bonding structure of DLC. Extensive experiments were carried out to examine the tribological behaviour of the DLC/52100 system. A metal intermediate layer can help tremendously in wear resistance. The results are optimistic and may lead to useful applications.
\end{abstract}

Keywords. Diamond-like carbon films; ion-beam assisted deposition.

\section{Introduction}

Diamond has many unique properties. High hardness-diamond is number one on the Mohs scale - is one of the most notable. Scientists have been trying to make diamond artificially for many years. Bundy of General Electric achieved it in 1954, by using high temperature and super high pressure with Ni catalyst (Bundy 1955). Since then a number of attempts have been made to prepare diamond by chemical vapour deposition (CVD) decomposition of hydrocarbons and $\mathrm{CCl}_{4}$ on diamond seeds (Spitsyn et al 1988). Deryagin et al (1976) first reported success in preparing diamond by CVD on nondiamond substrates. This work stimulated an avalanche of research on studies of low-temperature and low-pressure preparation of diamond, and new methods and approaches increasingly emerged.

A number of factors affect the formation and properties of these low-temperature low-pressure diamonds, such as gas composition, temperature, substrates, etc. There is also the problem of adhesion at the interface. Many of the prevailing methods employ rather high substrate temperatures (e.g. $800-1000^{\circ} \mathrm{C}$ ) and are quite particular of the substrates themselves. Among all the existing methods ion beam-assisted deposition (IBAD) is probably the one that uses the lowest temperature (room temperature) and can be applied to any substrate. Of course, it is also probably the method furthest from the equilibrium state of diamond. Therefore, so far only diamond-like carbon (DLC) films can be obtained (see figure 1). However, these DLC can be optimized to have excellent properties and to have important potential applications. In fact they even possess some advantageous aspects compared to diamond. This constitutes the motivation of our research programme. 


\section{IBAD and the equipment}

IBAD is a new version of ion implanation. Figure 2 is a schematic diagram to show the difference. It maintains the advantage of the useful energy carried by the charged ions and adds the advantage of building up of an overlayer.

The energy of ion beams is a very useful tool to enhance chemical reactions. With this in mind, we have synthesized 17 metallic nitrides at room temperature since 1980 (Li 1986). The energetic ions can induce an avalanche of primary and secondary

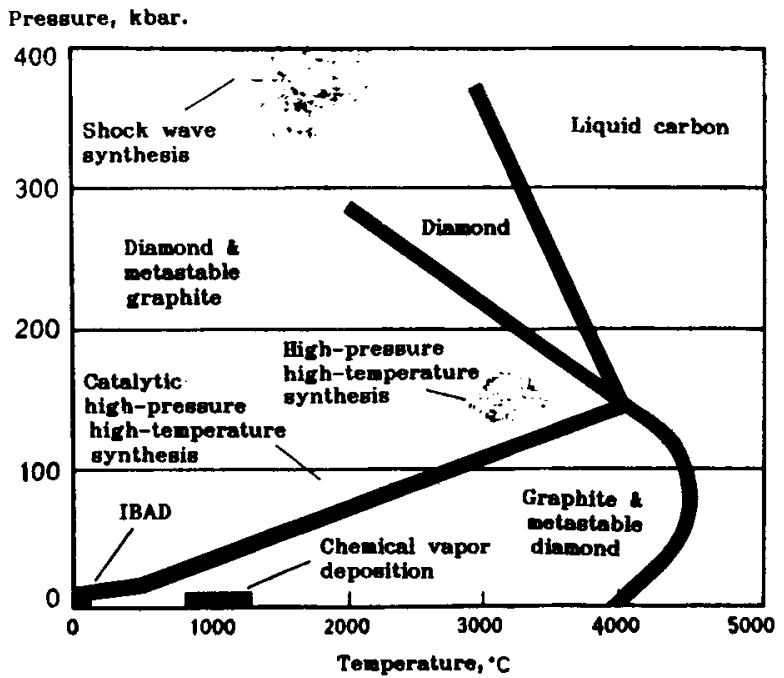

Figure 1. T-P phase diagram of carbon.

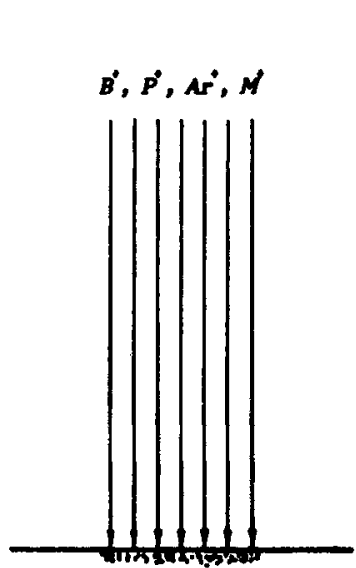

Ion

Ipplantecton

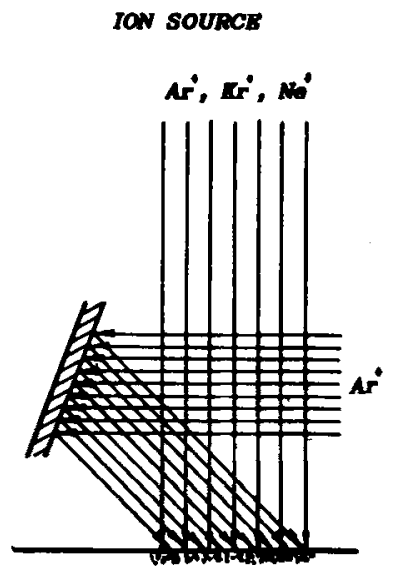

Dronecic Booal

Inplentation

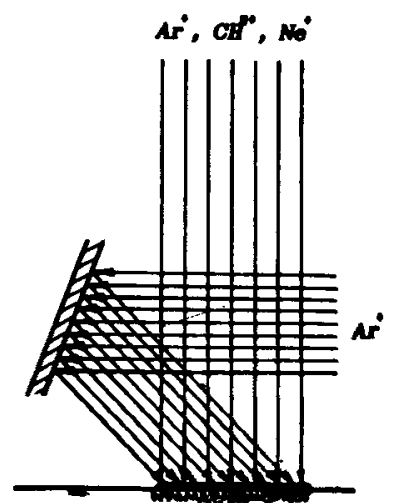

Ion Bean Andoted

Depoutton

(Minine Dopodtion)

Figure 2. Schematic diagram of ion implantation, dynamic recoil implantation and ion beam assisted deposition (IBAD). 

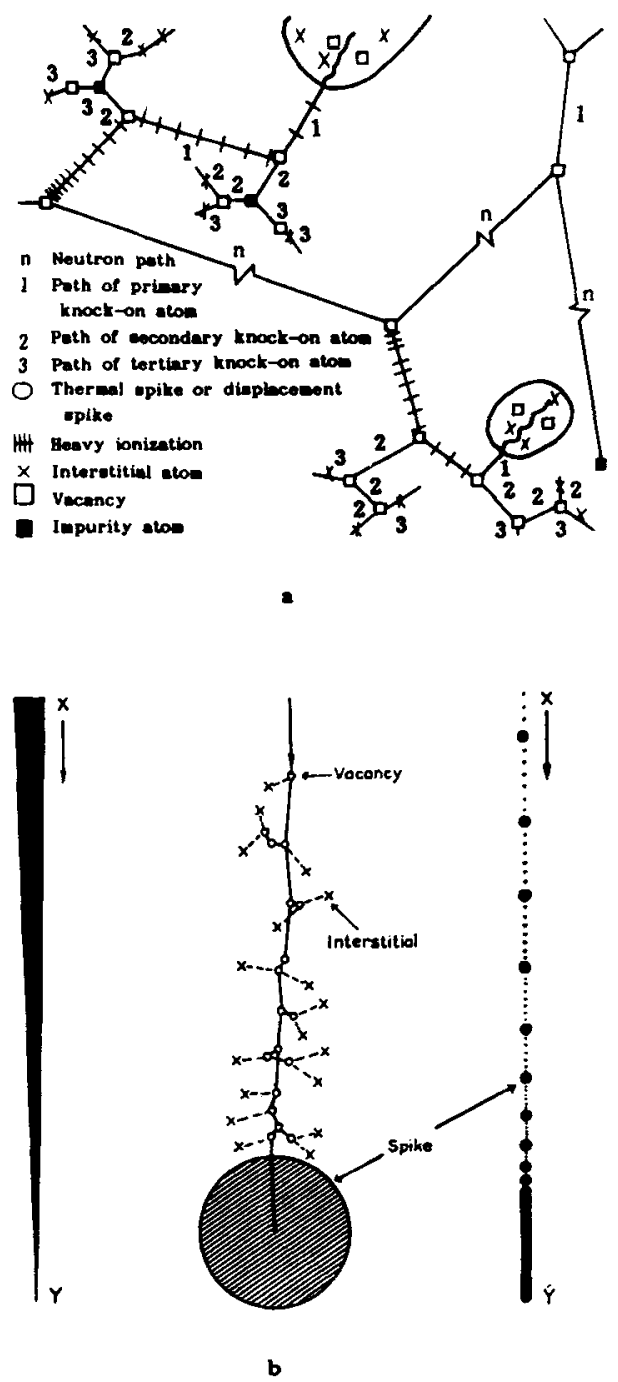

Figure 3. a. Collision cascade induced by an energetic particle and $\mathbf{b}$. thermal spikes and displacement spikes.

recoil atoms whose kinetic energy (say $100 \mathrm{eV}$ ) can easily surpass the required reaction activation energy $(0.5 \mathrm{eV}$ ) (figure 3a). Furthermore a series of thermal spikes and displacement spikes can be created on the paths of their trajectories (figure $3 \mathrm{~b}$ ). The temperature of the spike is estimated to be about $3800 \mathrm{~K}$ and the duration about $10^{-11} \mathrm{sec}$ (Weissmantel et al 1980). Therefore the requirements of a chemical reaction can be satisfied both energy-wise and time-wise. This process, which we label 'collision-activated reaction', can bring a high-temperature process to room temperature (see figure 4).

The energetic ions serve another important function, i.e. to cause an interface mixing. Figure 5 is a simulated picture to illustrate this point. This ion-mixing process can sometimes form new phases in the region. This effect can generally lead to high interfacial adherence. In this case, it offers the potential to obtain a 'coherent' interface, 


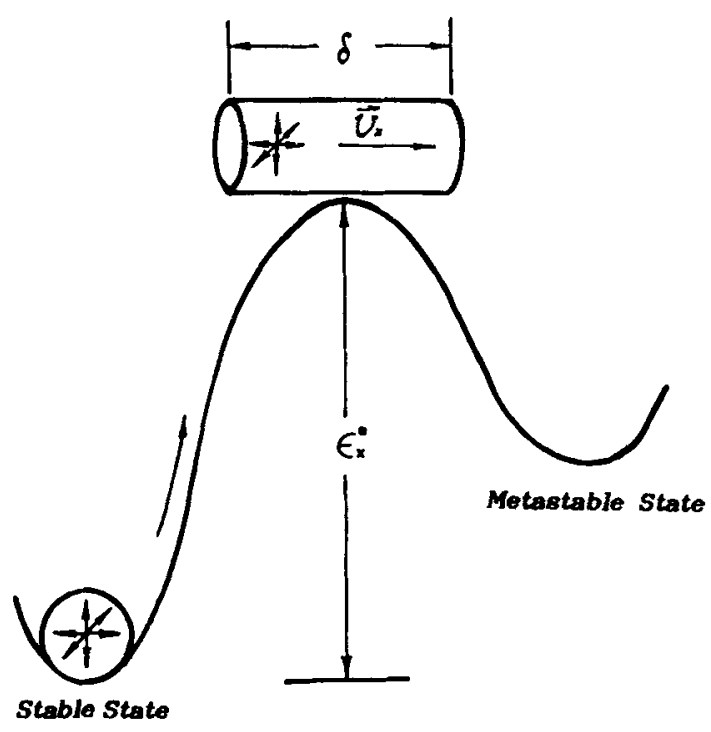

$\epsilon_{*}^{*}$...... $10 \mathrm{~kJ} / \mathrm{mol} ; 0.5 \mathrm{eV}$;

a. ...... X-component of atomic velocities abng the direction of tranglation;

$\delta$...... Activation length;

$\tau=\delta / \partial_{x} \sim 1014$.

Figure 4. Energy associated with the impinging particle can bring the state from stable to metastable. The collision-activated complex has a long enough lifetime.

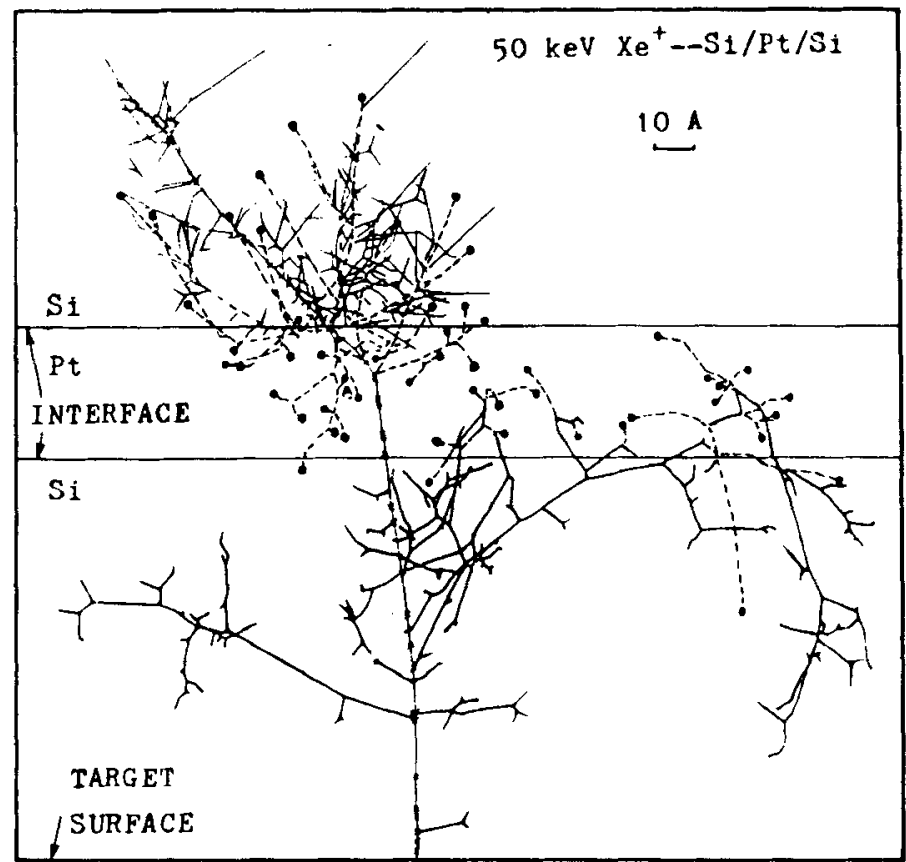

Figure 5. An energetic particle-induced interface mixing (a computer simulation). 
not relying on epitaxial growth but on interfacial mixed bonding. Lattice misfit is no longer a problem.

To sum up, it may be stated that a low-temperature (room temperature) process, a strong interfacial adhesion, and the freedom in choice of substrates are the unique advantages of the IBAD route for preparation of many surface coatings, including DLC films,

The IBAD system used for the present studies was developed in 1990 in this laboratory. Figure 6 is a schematic diagram of it. Three Kaufmann ion sources are available. The source labelled 7 is a specially designed high-density source used for sputtering with generally a voltage of $24 \mathrm{kV}$ and a current of $100-150 \mathrm{~mA}$. Source 1 is for highenergy bombardment, with voltage from $3 \mathrm{kV}$ to $40 \mathrm{kV}$. Source 8 is for low-energy bombardment with voltage from 100 to $700 \mathrm{~V}$. The part labelled 2 is a rotatable target holder, water cooled. Four targets can be attached. This number of targets together with a variation of ion species for bombardment can bring about many different combinations. Part 6 is a water-cooled specimen holder; it may be water-cooled or heated up to $400 \mathrm{C}$. The vacuum system consists of a set of mechanical and diffusion pumps to make a base pressure of about $2 \times 10^{-4} \mathrm{~Pa}$. Such an IBAD system proves to be quite versatile, and not only offers a great number of possibilities for film composition. from single element to various alloys and compounds, but also for ordinary sputtering or ion-assisted sputtering from ions from $100 \mathrm{eV}$ to $40 \mathrm{keV}$.

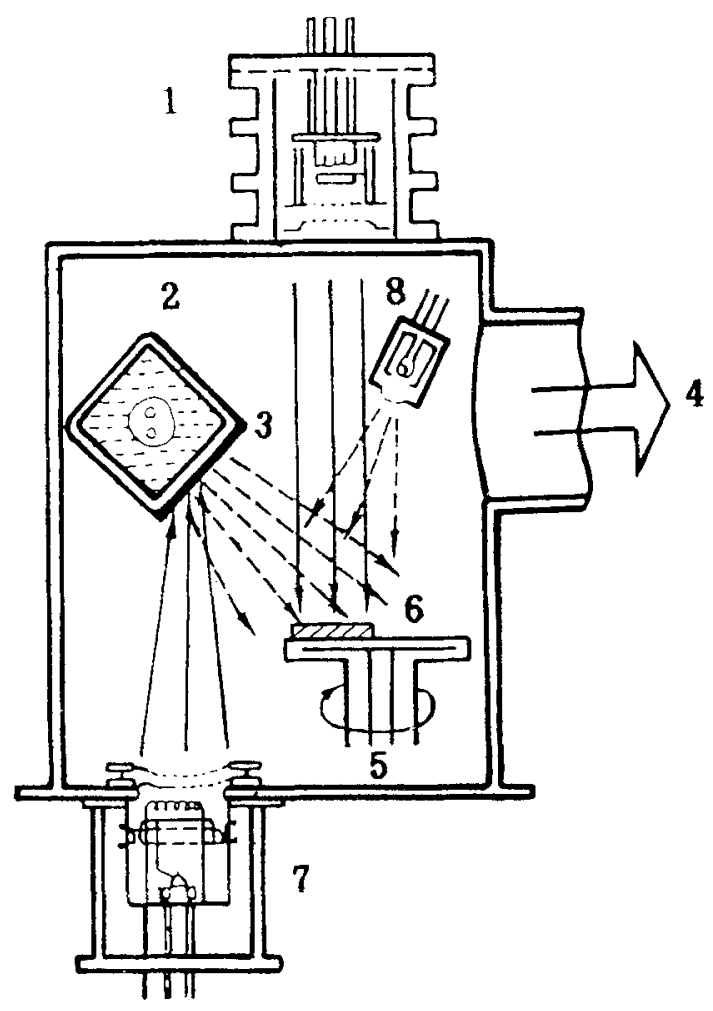

Figure 6. A schematic diagram of the IBAD system. 1. Medium energy ion source, 2. fourfold rotatable target holder. 3. target. 4. vacuum system, 5. rotatable sample holder, 6. substrate, 7. sputtering ion source for deposition and 8. low energy ion source. 


\section{Experimental scheme}

To study DLC deposition with the above equipment, both ion beam deposition (IBD) and dual ion beam sputtering (DIBS) were used. Table 1 shows the schemes so far experimented. The process parameters involve direct deposition or deposition by sputtering, the carbon source with or without $\mathrm{H}_{2}$, bombarding energy from $100 \mathrm{eV}$ to $25 \mathrm{keV}$, the species, such as $\mathrm{Ar}^{+}, \mathrm{Ne}^{+}, \mathrm{N}^{+}$and $\mathrm{CH}^{n+}$, the substrate materials, e.g. $\mathrm{Si}(111)$ wafer, glass, $\mathrm{NaCl}$, AISI 52100 steel, etc.

\section{The microstructure}

The appearance of the DLC films, as pictured by SEM, is always of a very smooth and flat surface, as shown in figure 7, the featureless morphology is typical of amorphous carbon. Roughness of the substrate can be somewhat improved after

Table 1. The IBAD experimental scheme.

\begin{tabular}{lll}
\hline & Sputtering & Bombarding species \\
\hline DIBS & Graphite target & $\mathrm{Ar}^{+}, \mathrm{Ne}^{+}, \mathrm{CH}^{n+}, \mathrm{N}^{+}$ \\
& $\mathrm{Ar}^{+}$sputtering & $\mathrm{Ne}^{+}+\mathrm{CH}^{n+}\left(\mathrm{Ne}^{+} / \mathrm{CH}^{n+}=1\right)$ \\
& $3-3.5 \mathrm{keV}, 100-150 \mathrm{~mA}$ & $\mathrm{~N}^{+}+\mathrm{CH}^{n+}$ \\
& & $\mathrm{CH}^{n+}$ \\
& & $\mathrm{CH}^{n+}+\mathrm{Ne}^{+}$ \\
& & $\mathrm{N}^{+}+\mathrm{CH}^{n+}$ \\
\hline
\end{tabular}

Substrates: $\mathrm{Si}(111), \mathrm{NaCl}, \mathrm{WC}, 52100$.
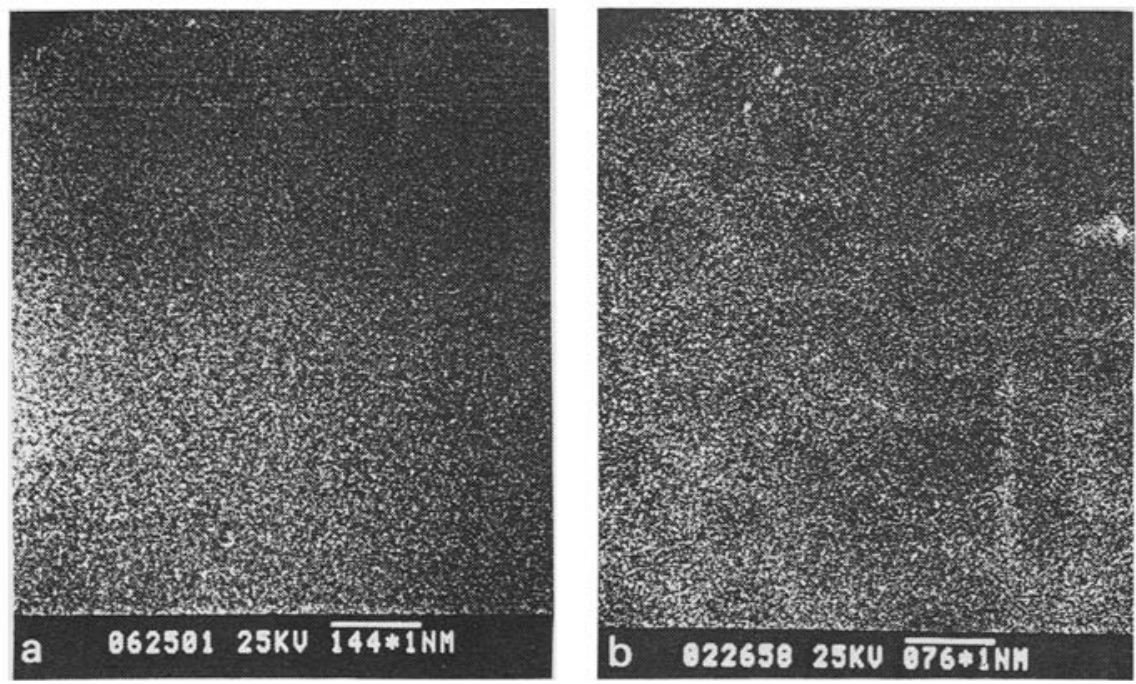

Figure 7. SEM photographs of DLC films prepared by (a) $200 \mathrm{eV}$ and (b) $15 \mathrm{keV} \mathrm{CH}{ }^{n+}$ bombardment. 

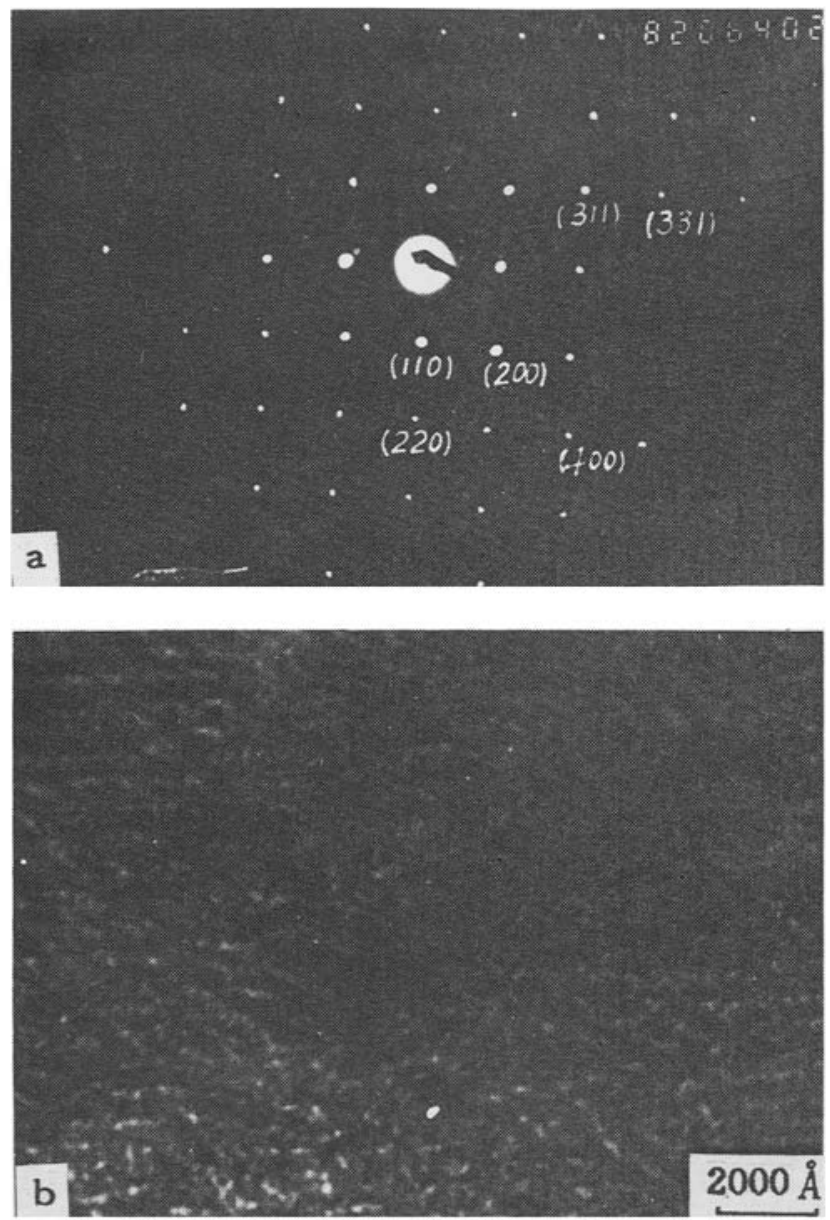

Figure 8. (a) Selected-area diffraction of DLC films and (b) TEM image of surface morphology.

deposition; Ra (roughness average) decreased from $0.024 \mu \mathrm{m}$ to $0.016 \mu \mathrm{m}$ in one case. This smoothness of coating is considered to be a useful characteristic of the DLC films. Figure 8a shows the diffraction spots of some crystals dispersed on amorphous matrix of DLC films, as seen in figure $8 \mathrm{~b}$. Their spacings are identified to be 2.57 , $1.89,1.34,1.2$ and $0.94 \AA$; for comparison, those of cubic diamond: $d(110)=2.52$, $d(200)=1.78, d(210)=1.26, d(311)=1.08$ and $d(400)=0.89 \AA$ (Min et al 1992). Therefore some of the films clearly contain dispersed diamond particles.

Thickness of the film generally used is over $600 \mathrm{~nm}$ as calculated from the Rutherford backscattering (RBS) spectra, such as shown by figure 9 .

The composition corresponding to figures 7 and 8 was determined by Auger electron spectroscopy (AES) (figure 10). Some oxygen appears on the surface but after $3 \mathrm{~min}$ $\mathrm{Ar}^{+}$sputtering etching at $1 \mathrm{keV}$, the films show only carbon atoms.

However, in the cases when hydrocarbons are employed, no attempts have been made to determine the hydrogen content. 


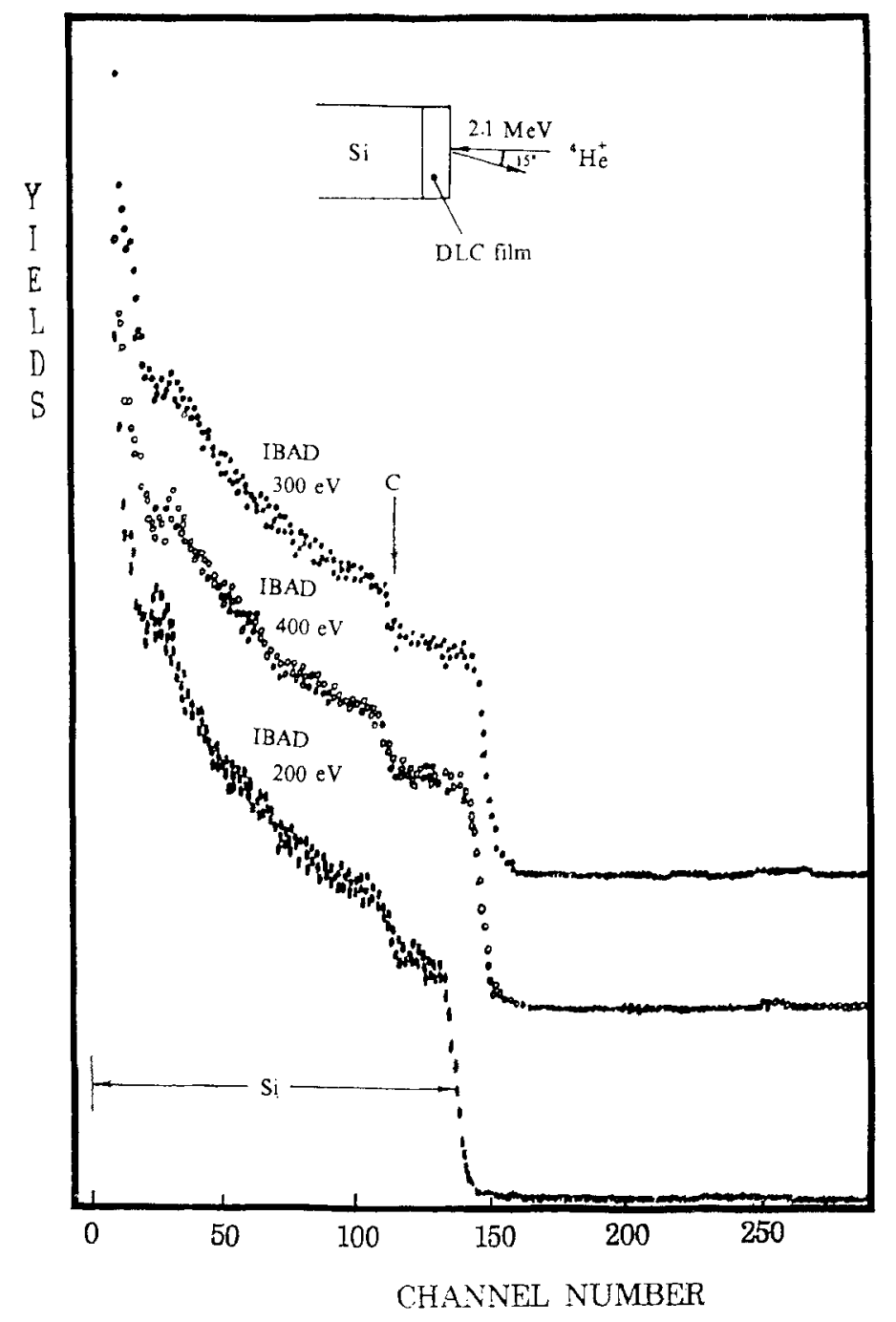

Figure 9. RBS spectra of synthesized DLC films.
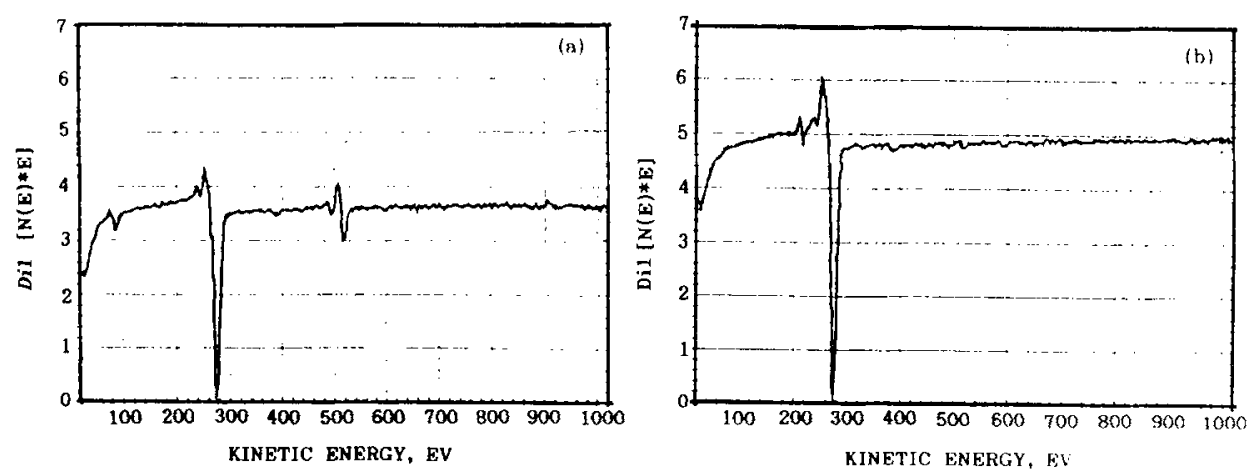

Figure 10. AES of carbon films prepared by IBAD: (a) surface spectrum, (b) spectrum after sputtering $3 \mathrm{~min}$ at $1 \mathrm{keV}$. 


\section{Bonding in DLCs}

The nature of bonding in DLC has been investigated using Raman spectroscopy, $\mathrm{X}$-ray photoelectron spectroscopy (XPS) and AES.

Typical AES spectra of diamond, graphite and DLC are shown together for comparison in figure 11a (Moravec and Orent 1981). The most distinguishable feature of the diamond AES fine structure from that of graphite is the shoulder at the right (higher energy) side of the $250 \mathrm{eV}$ peaks. The diamond shoulder goes up while the graphite shoulder goes down, and in DLC the shoulder is in between.

Figures $11 \mathrm{~b}$ and $\mathrm{c}$ show the AES features of DLC prepared in the present study. It is clearly seen in all cases that the AES spectrum resembles the diamond spectrum more as the bombarding energy gradually decreases; 200 to $400 \mathrm{eV}$ bombardment appears to offer the best result. It is also noticed that the trough (actually the peak point of the carbon KLL AES electrons) shifts gradually to higher energy as the bombarding energy decreases; so is the trend of the $250 \mathrm{eV}$ peaks. All these features could be taken as an indication that more $s p^{3}$ bonds are formed when the ion beam energy is around $200 \mathrm{eV}$.

Stronger evidence of this phenomenon can also be observed in the Raman spectra in figures $12 \mathrm{a}$ and $\mathrm{b}$, where the $1333 \mathrm{~cm}^{-1}$ peak becomes obvious also for a bombarding energy of $200-400 \mathrm{eV}$.

The XPS spectra point to similar trends (figure 13). There are three distinct spectral regions in the valence band of natural diamond (figure 13a) (Mizokawa et al 1987). Region I has a peak between 16 and $21 \mathrm{eV}$ which arises from $s$-like bonds, region II has a peak between 10 and $15 \mathrm{eV}$ representing the mixture of $s$ and $p$ characters, region III between 3 and $10 \mathrm{eV}$ is attributable to the $p$ bonds (Mizokawa et al 1987). Figures $13 b$ and $c$ show the spectra of DLC prepared by DIBS and IBD processes. Again, around $200-400 \mathrm{eV}$, the $s-p$ mixed bond comes to be more prominent. Figure 14 shows the change of $\mathrm{C} 1 s$ peak positions of DLC films prepared by IBD at bombarding energy between $15 \mathrm{keV}$ and $200 \mathrm{eV}$. It is very clear that as the energy is reduced from $15 \mathrm{keV}$ to $200 \mathrm{eV}$, the binding energy comes closest to that of pure diamond, $285.05 \mathrm{eV}$.

All the above spectra lead to an understanding of the structure of the DLC films. They are amorphous, but their content of $s p^{3}$ bonds may be increased by low-energy-

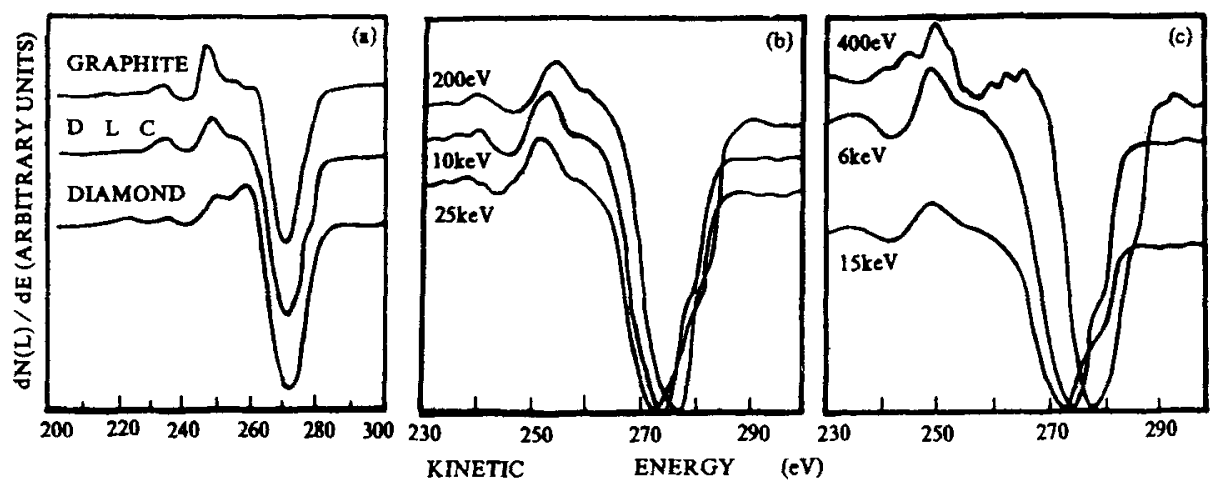

Figure 11. (a) AES of diamond, graphite, and typical DLC film, (b \& c) AES of DLC films prepared by DIBS (b) and IBD (c) both at different energies. 


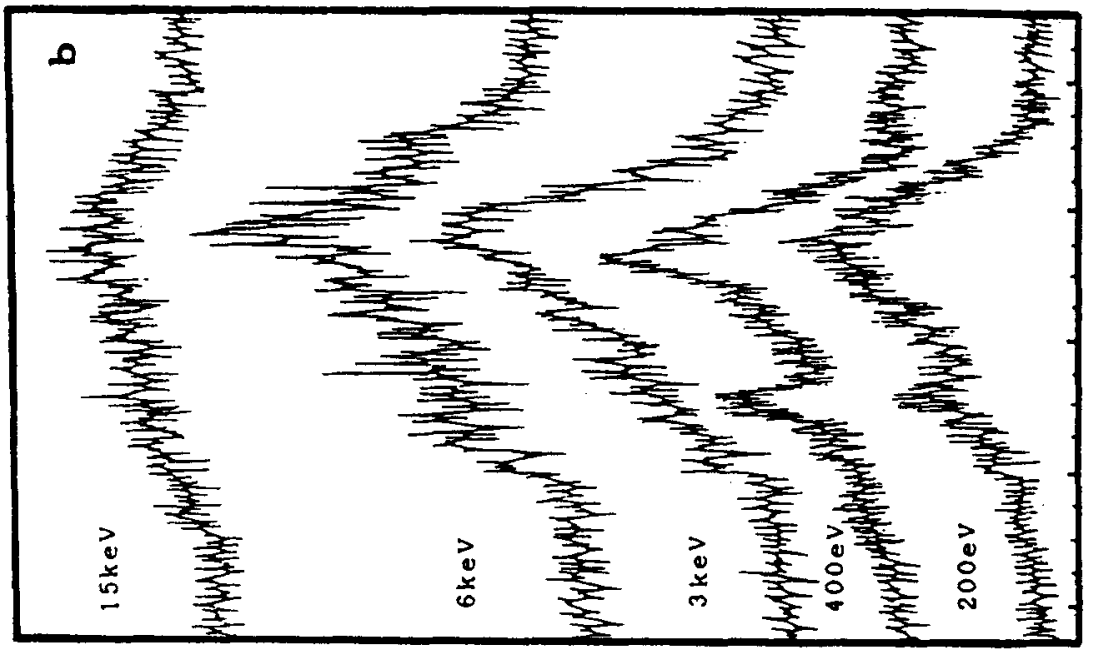

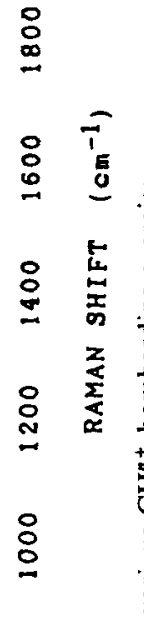

(SLIN KUYZLIGQY) RLISNZNI

a

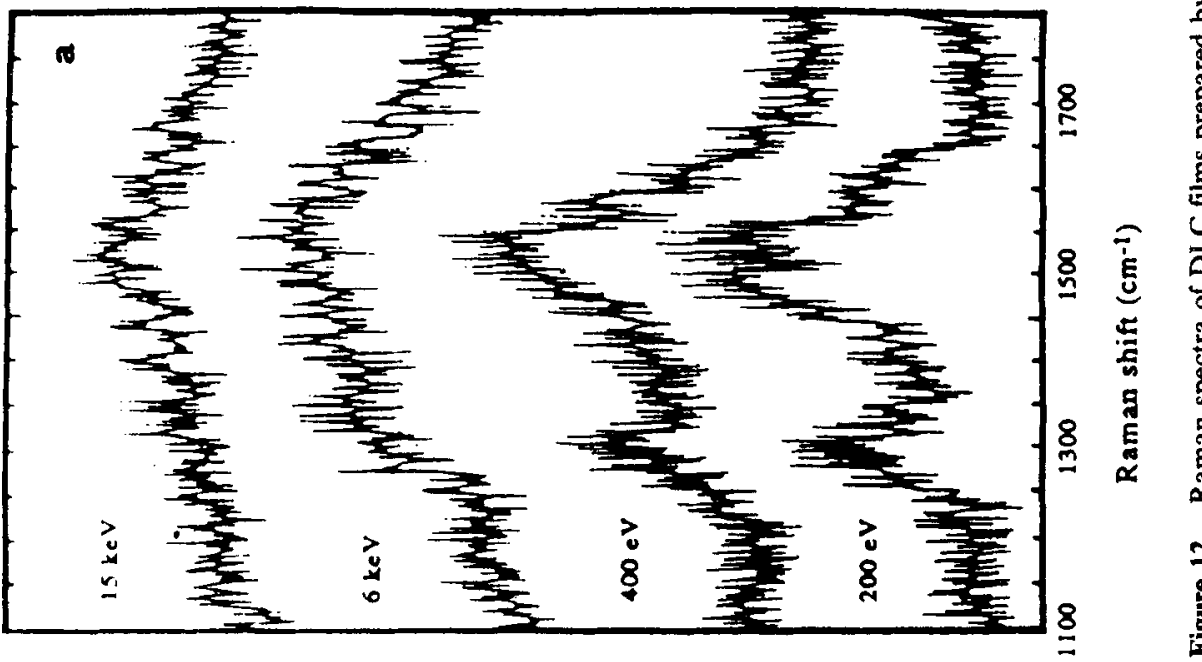

?

(sılun Kमejigde) Kı!suolu! 

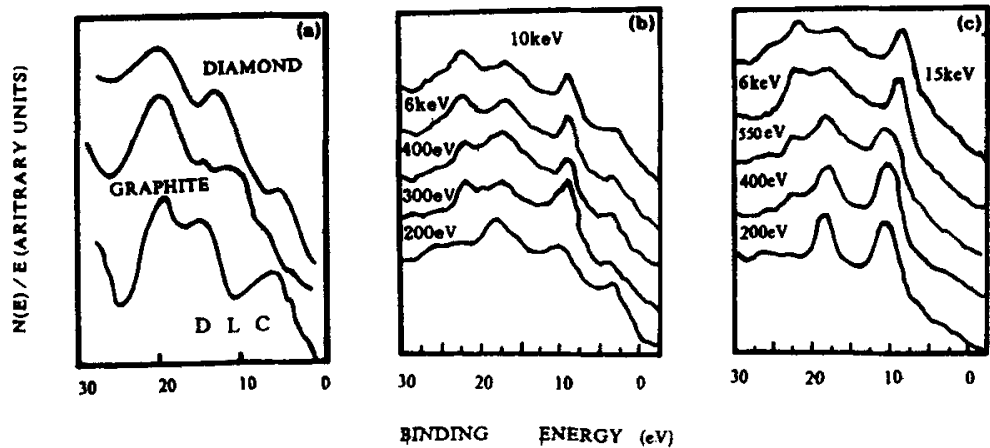

Figure 13. (a) XPS of diamond, graphite, and typical DLC film, (b \& c) XPS of DLC films prepared by DIBS (b) and IBD (c) both at different energies.

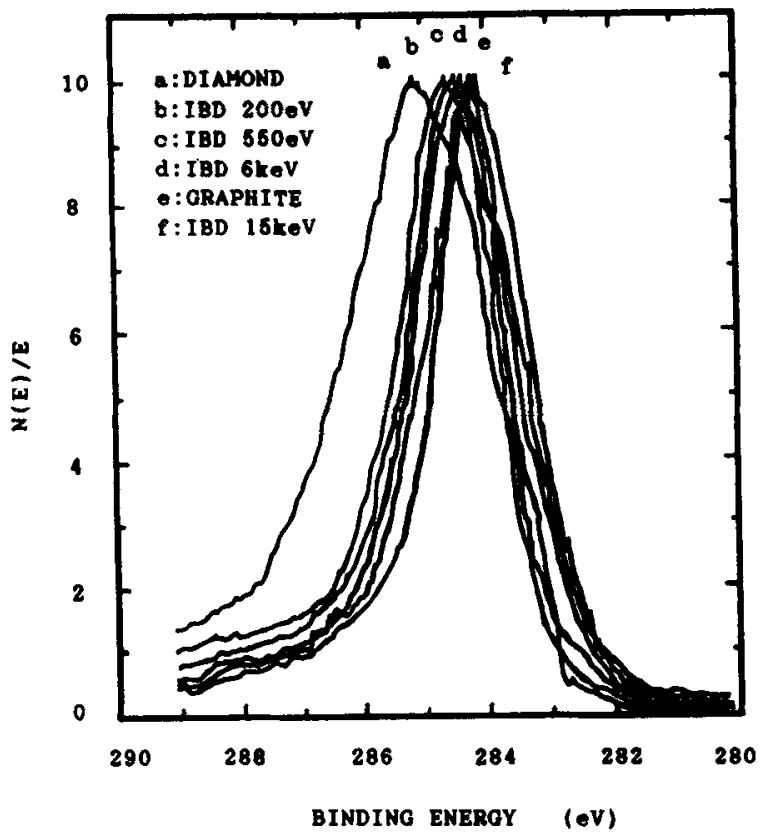

Figure 14. The main C1s peaks of diamond, graphite and DLC films prepared by IBD.

assisted deposition, i.e. they tend to be more diamond-like to a certain degree under certain processing conditions. With $\mathrm{Ne}^{+}$bombardment, dispersed diamond crystals can be present (see figure 8 ).

\section{Hardness of DLC and the bombarding energy}

Hardness is one of the properties of DLC that one is most concerned with. Table 2 shows the results of the measurements.

Two things are pointed out by these data. Between $3 \mathrm{keV}$ and $25 \mathrm{keV}$ bombarding energy the hardness is not quite high and is not sensitive to energy variation. However, 
Table 2. Hardness $\left(\mathrm{kgf} / \mathrm{mm}^{2}\right)$ of DLC films bombarded by $\mathrm{CH}^{n+}$ under different energies (substrate: $\mathrm{Si}(111)$ ).

\begin{tabular}{|c|c|c|c|c|c|c|c|c|c|c|}
\hline $\begin{array}{l}\text { Bombarding } \\
\text { energy }(\mathrm{eV})\end{array}$ & & 200 & 300 & 400 & 550 & 3000 & 6000 & 10000 & 15000 & 25000 \\
\hline \multirow{2}{*}{ DIBS } & $10 \mathrm{~g}$ & & & & & 1550 & 1630 & 2180 & 1560 & 1600 \\
\hline & $20 \mathrm{~g}$ & 5100 & 3250 & 2720 & & & & & & \\
\hline IBD & $10 \mathrm{~g}$ & 3000 & & 3500 & 2700 & 1395 & 1290 & 1550 & 1450 & \\
\hline
\end{tabular}

Table 3. Hardness $\left(\mathrm{kgf} / \mathrm{mm}^{2}\right)$ of DLC films synthesized under different ion bombardments (substrate: $\mathrm{Si}(111)$ ).

\begin{tabular}{|c|c|c|c|c|c|}
\hline $\begin{array}{l}\text { Bombarding } \\
\text { energy }(e V)\end{array}$ & & 200 & & & \\
\hline $\begin{array}{l}\text { Bombarding } \\
\text { ions }\end{array}$ & $\mathrm{Ne}^{+}$ & $\mathrm{CH}^{n+}+\mathrm{Ne}^{+}$ & $\mathrm{CH}^{n+}+\mathrm{Ne}^{+}+\mathrm{Ar}^{+}$ & $\mathrm{CH}^{n+}$ & $\mathbf{N}^{+}$ \\
\hline $\begin{array}{l}\text { Ratio of } \\
\text { gas pressure }\end{array}$ & 1 & $1: 1$ & $2: 1: 1$ & 1 & 1 \\
\hline $\begin{array}{l}\text { Knoop } \\
\text { hardness } 10 \mathrm{~g}\end{array}$ & 4010 & 4540 & 4300 & 3500 & $5260^{*}$ \\
\hline
\end{tabular}

* The substrate is the disc of WC.

at $200-550 \mathrm{eV}$, the hardness has much higher values, particularly in the case of $\mathrm{Ar}^{+}-\mathrm{CH}^{n+}$ DIBS, where the highest value is reached at $200 \mathrm{eV}$ bombardment.

Table 3 shows the hardness of the DLC films synthesized under different ion bombardments. It indicates that DLC films with $200-400 \mathrm{eV}$ ion-assisted bombardment usually have high hardness of $3500-5000 \mathrm{kgf} / \mathrm{mm}^{2}$.

The high hardness in the $200-400 \mathrm{eV}$ range of bombarding energy obviously is connected to the bonding structure of the films as discussed in the previous section.

\section{Tribological properties}

For practical mechanical applications one has to examine the actual tribological behaviour of the DLC films and some other important properties. Two schemes of tribological measurements were made. They are illustrated by figures 15 and 16 .

Figure 15 shows a reciprocal version. The wear track created has a length of $2 \mathrm{~mm}$. With a ball of $9.5 \mathrm{~mm}$ in diameter, it is estimated that a load of $2 \mathrm{~N}$ corresponds to a contact stress of $0.8 \mathrm{GPa}$. Most previous measurements (Braum 1989; Kobs et al 1991; Ochsner et al 1991; Bhattacharya et al 1991) have been made under 1 or $2 \mathrm{~N}$ loads. For actual bearing operations, however, the contact stress may be up to 3-5 GPa. Therefore the tribological behaviour of DLC films under larger loading should be pursued. AISI 52100 steel is used for the substrate to simulate practical combination. Load employed ranged between 2 and $30 \mathrm{~N}$, corresponding to contact stress of $0.8-2 \cdot 15 \mathrm{GPa}$. During the wearing process, the friction coefficient can be 


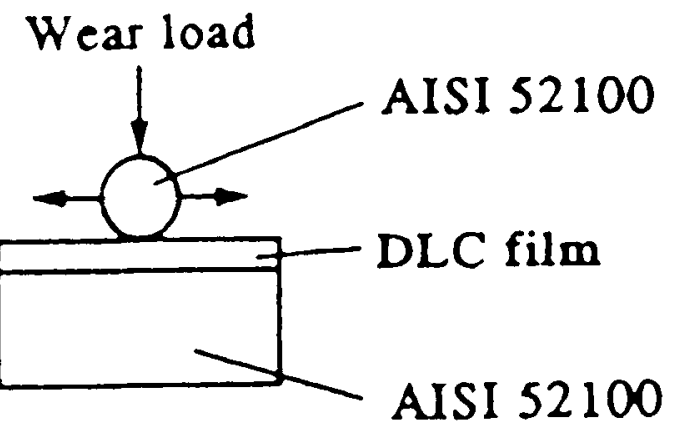

Figure 15. A schematic diagram of the reciprocal ball on disc tribometer. Motion, back and forth; stroke, $2 \mathrm{~mm}$; frequency, $10 \mathrm{~Hz}$; ball diam. $9.5 \mathrm{~mm}$; disc diam. $28 \mathrm{~mm}$; disc thickness $2 \mathrm{~mm}$.

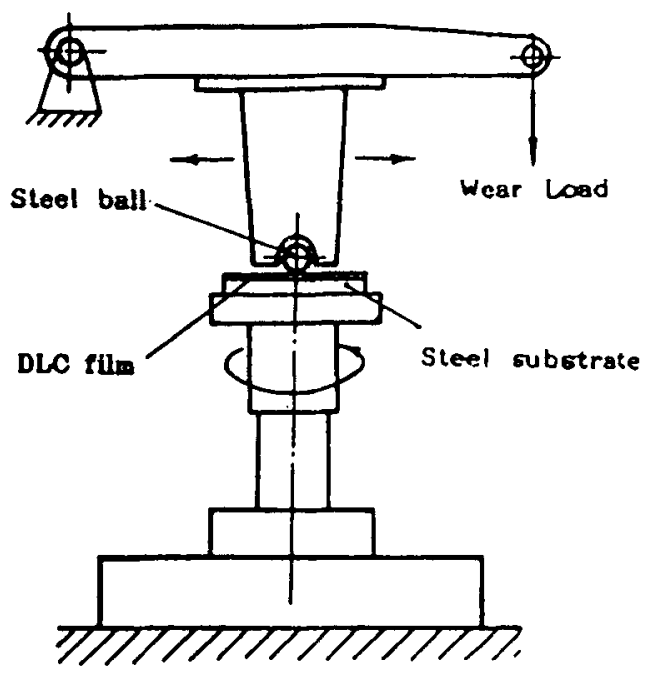

Figure 16. A schematic diagram of the revolving tribometer.

Table 4. Wear properties of DLC films under different wear loads*.

\begin{tabular}{lcccccc}
\hline $\begin{array}{l}\text { Load }(\mathrm{N}) \\
\begin{array}{l}\text { Sliding } \\
\text { distance }(\mathrm{m})\end{array}\end{array}$ & 2 & 5 & 10 & 15 & 20 & 30 \\
$\begin{array}{l}\text { Groove wear } \\
\text { volume }\end{array}$ & 72 & 72 & 72 & 60 & 48 & 12 \\
$\left(\times 10^{6} \mathrm{~mm}^{3}\right)$ & 7.52 & 219.59 & 409.71 & 556.6 & 706.48 & 2733.02 \\
$\begin{array}{l}\text { Wear coeff. } \\
\left(K \times 10^{6}\right)\end{array}$ & 0.94 & 10.98 & 10.24 & 11.132 & 13.25 & 136.65 \\
AWN & 6.02 & 4.959 & 4.99 & 4.95 & 4.87 & 3.86 \\
\hline
\end{tabular}

*All tests were carried out at a temperature of about $27^{\circ} \mathrm{C}$ and relative humidity of $50 \%$. 


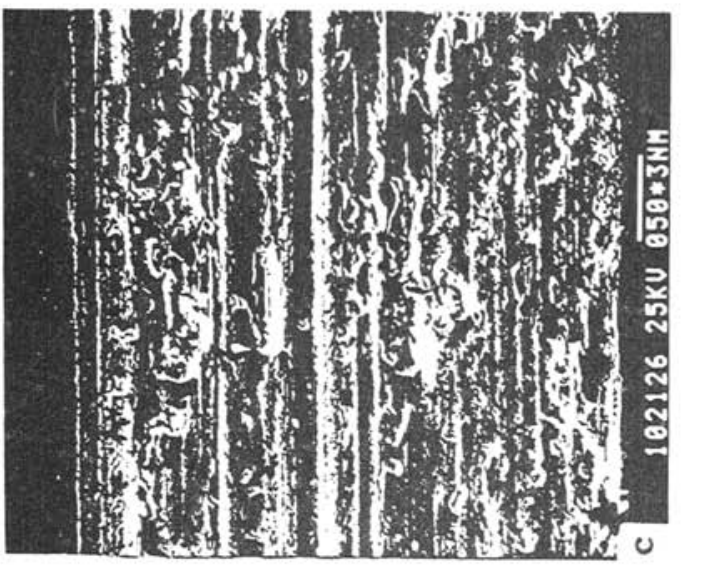

忥

趈

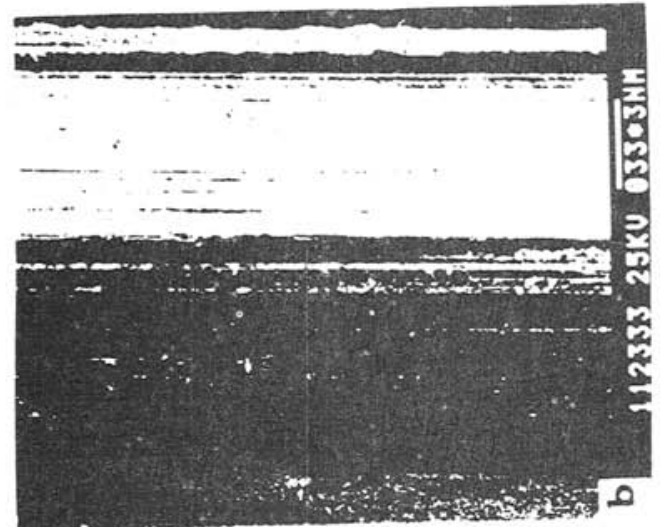

$\stackrel{90}{\underline{\Xi}}$

:

导

$\sigma$

s

:

惫官

突

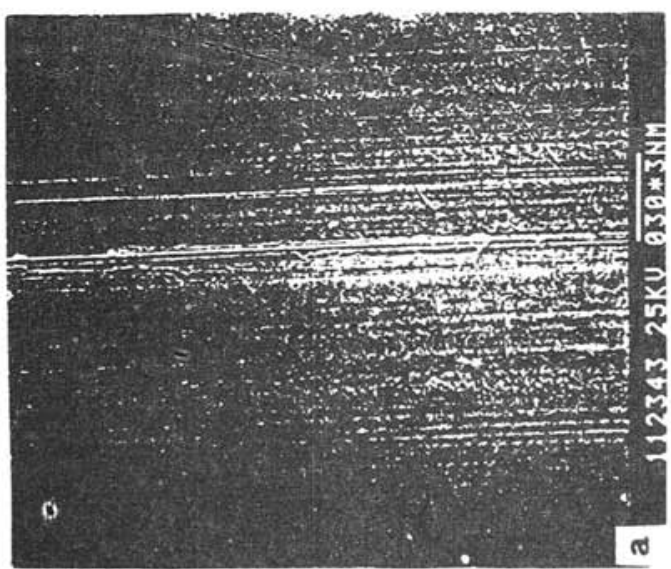

3

药

点

z

4

을

ह

$\sum \sum_{\bar{m}}$

要

$\div \frac{\pi}{3}$

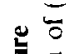

는 윰 


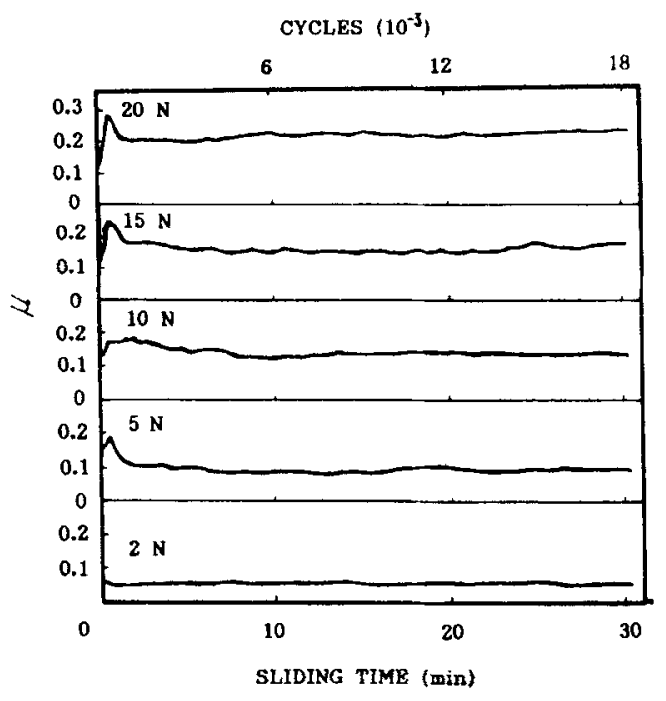

Figure 18. Friction coefficient vs sliding time for loads of $2 \mathrm{~N}, 5 \mathrm{~N}, 10 \mathrm{~N}, 15 \mathrm{~N}$ and $20 \mathrm{~N}$ for DLC films deposited on the 52100 steel.

monitored and evaluated on a chart recorder as a function of wearing time. Volumetric wear can be measured and calculated to offer two parameters for evaluation, i.e.

$$
\begin{array}{ll}
\text { wear coefficient: } & K=\left(\delta V H_{k}\right) /(S P) \\
\text { anti wear number: } & \mathrm{AWN}=-\log K .
\end{array}
$$

Here $\delta V$ is volumetric wear, $H_{k}$ is knoop hardness, $S$ is distance travelled, and $P$ is wear load.

Results for IBD DLC deposited with an energy of $200 \mathrm{eV}$ are shown in table 4 . SEM pictures of the tracks are shown in figure 17, the coefficient of friction in figure 18.

The data lead to the following facts: The coefficient of friction of DLC under $2 \mathrm{~N}$ is very low, only 0.05 . Even at a very high load of $20 \mathrm{~N}$, the coefficient of friction only goes up to $0 \cdot 2$. This is much lower than the value of 0.75 for AISI 52100 steel. The surface is only slightly scratched after wearing under a load of $5 \mathrm{~N}$ after $30 \mathrm{~min}$ (figure 17a). The wear track in the case of load of $2 \mathrm{~N}$ is too shallow to be shown under SEM and the wear coefficient is two orders less than in the other tests shown in table 4 , and AWN is roughly double that under $30 \mathrm{~N}$. This proves that hard DLC film has a strong wear-resistance under a load of $2 \mathrm{~N}$ and a steady wearing can proceed for a long time without lubrication. An important fact should be pointed out that AWNs do not change much between 5 and $15 \mathrm{~N}$ loads. For the case of $15 \mathrm{~N}$, which represents a very severe test, the coefficient of friction can still remain quite low $(0 \cdot 15)$ even when the substrate starts to expose itself. This low friction coefficient may originate from the $s p^{2}$ component of bonding in the film and effectively reduce the wear rate. Therefore the presence of $s p^{2}$ could be an advantageous aspect for the tribological applications of DLC films (Braum 1989; Miyake and Kaneko 1991).

DIBS offer similar results. Figure 19 gives the relationship of friction coefficient against load, up to $56 \mathrm{~N}$, at which the wear carries entirely on the 52100 substrates. 


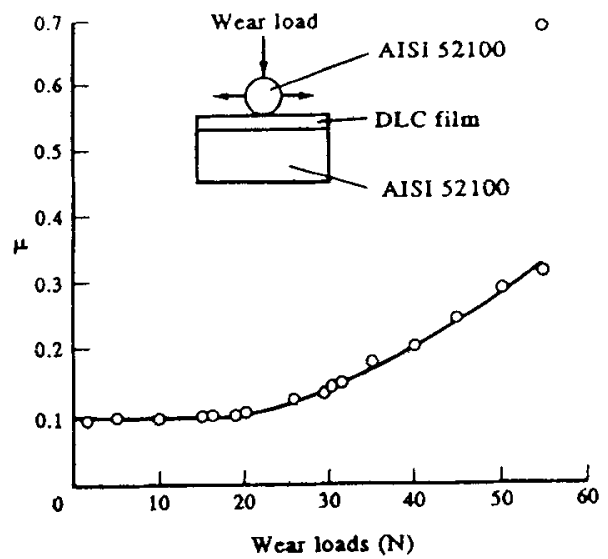

Figure 19. Friction coefficient values for DLC films as a function of increasing wear load.

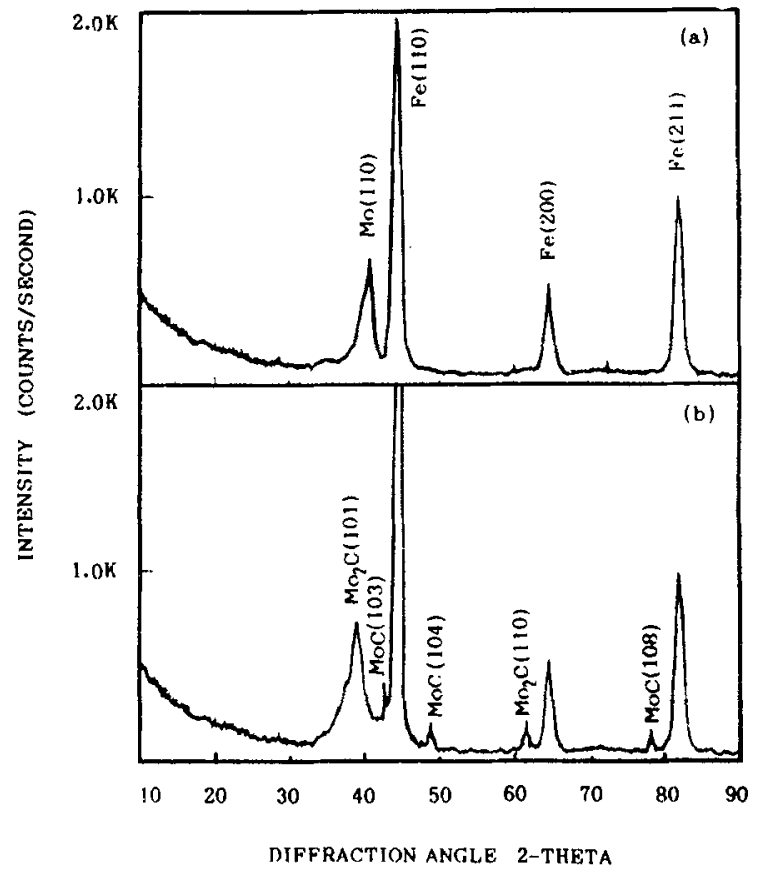

Figure 20. X-ray diffraction patterns of (a) Mo film and (b) $\mathrm{DLC} / \mathrm{Mo}$ film on AISI 52100 steel.

\section{Dynamic mixing in interlayer interfaces on tribological enhancement}

Amorphous DLC films with low friction coefficients are very suitable for applications in mechanical devices. However, the adhesion of DLC films often decreases with increasing thickness of DLC films deposited on AISI 52100 steel. This limits DLC films to use as wear-proof coating under heavy load condition. In order to enhance 
the adhesion of DLC film to steel substrate, a thin metal film such as molybdenum (Mo) was first prepared on the steel substrate and then DLC films deposited on it. Prior to deposition, atomic mixing was carried out by $\mathrm{Ar}^{+}$-sputtering a pure Mo plate to deposit Mo atoms on the substrate with simultaneous bombardment by $35 \mathrm{keV}$ and $25.5 \mu \mathrm{A} / \mathrm{cm}^{2} \mathrm{Ar}^{+}$to create a wide atomic mixing band of $\mathrm{Mo} / \mathrm{Fe}$ around film/substrate interface. Similarly a wide intermixed DLC/Mo interface was then fabricated by sputtering a high-density graphite target with other conditions identical to those in the formation of the above atomic-intermixed $\mathrm{Mo} / \mathrm{Fe}$ interface.

The X-ray diffraction patterns of DLC/Mo/steel substrate are shown in figure 20 , and the element concentration profiles around both $\mathrm{Mo} / \mathrm{Fe}$ and DLC/Mo interfaces are depicted in figure 21. It is obvious that due to high-energy $\mathrm{Ar}^{+}$bombardment, significant atomic intermixing occurred in both $\mathrm{Mo} / \mathrm{Fe}$ and DLC/Mo interfaces (figure 21) and the molybdenum carbides, $\mathrm{MoC}$ and $\mathrm{Mo}_{2} \mathrm{C}$, were formed in the DLC/Mo interfaces (figure 20). These metallic compounds are very effective in hindering the diffusion of carbon atoms into steel substrates (as seen in figure 21). The existence of the molybdenum carbides and the atomic intermixing at both $\mathrm{Fe} / \mathrm{Mo}$ and Mo/DLC interfaces would greatly enhance the adhesion of DLC films to steel substrate and prevent DLC films from exfoliation in application.

The coefficients of friction as a function of the wear time under different wear loads are depicted in figure 22. It is notable that even when the wear load increases to $25 \mathrm{~N}$, the coefficient still remains in the range $0.06-0 \cdot 14$, which is much less than that in current literature (Raveh et al 1993).

The typical morphology of the wear groove is shown in figure 23. As the wear load was increased from $2 \mathrm{~N}$ to $25 \mathrm{~N}$, the worn grooves on DLC films were still quite even and flat, and no exfoliation occurred. This demonstrates that the DLC film has very good adhesion to $\mathrm{Mo} /$ steel substrate.

Spultering rate: $-100 \AA /$ min.

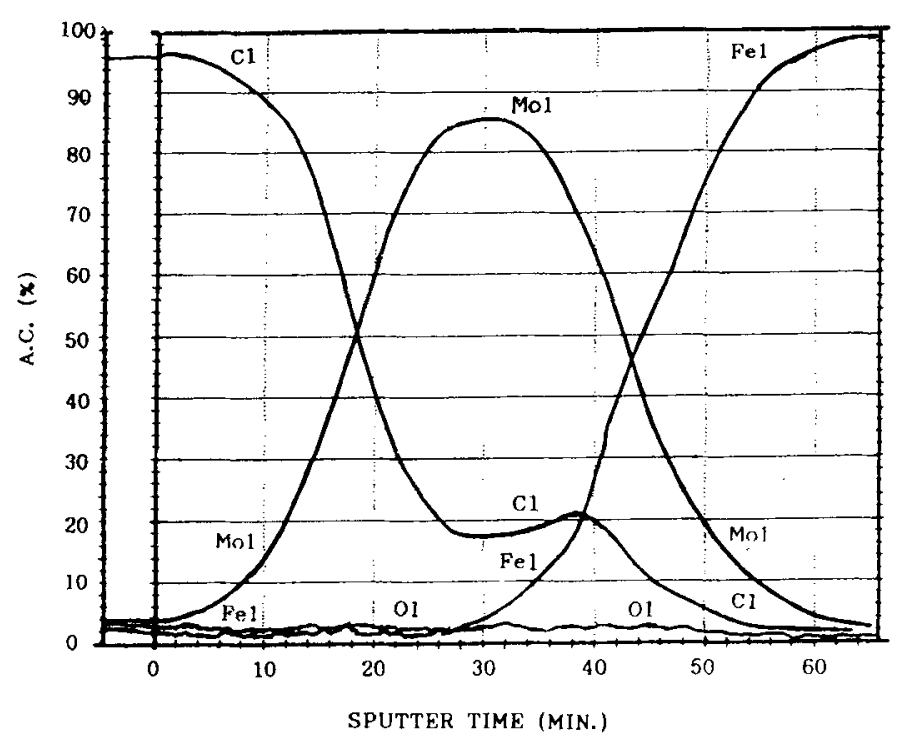

Figure 21. The sputter-etching curve of AFS in the atomic mixing area around DLC/Mo/ AISI 52100 steel interfaces. 


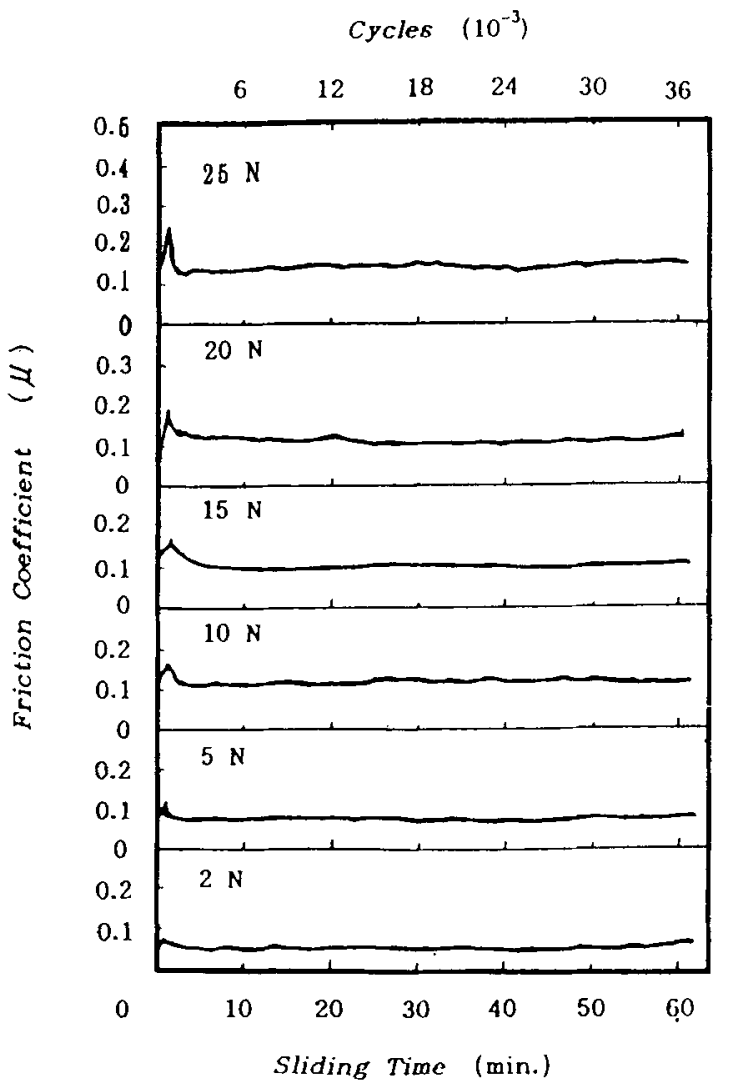

Figure 22. The friction coefficient $(\mu)$ vs the wear load measured under the experimental condition shown in table 5 .
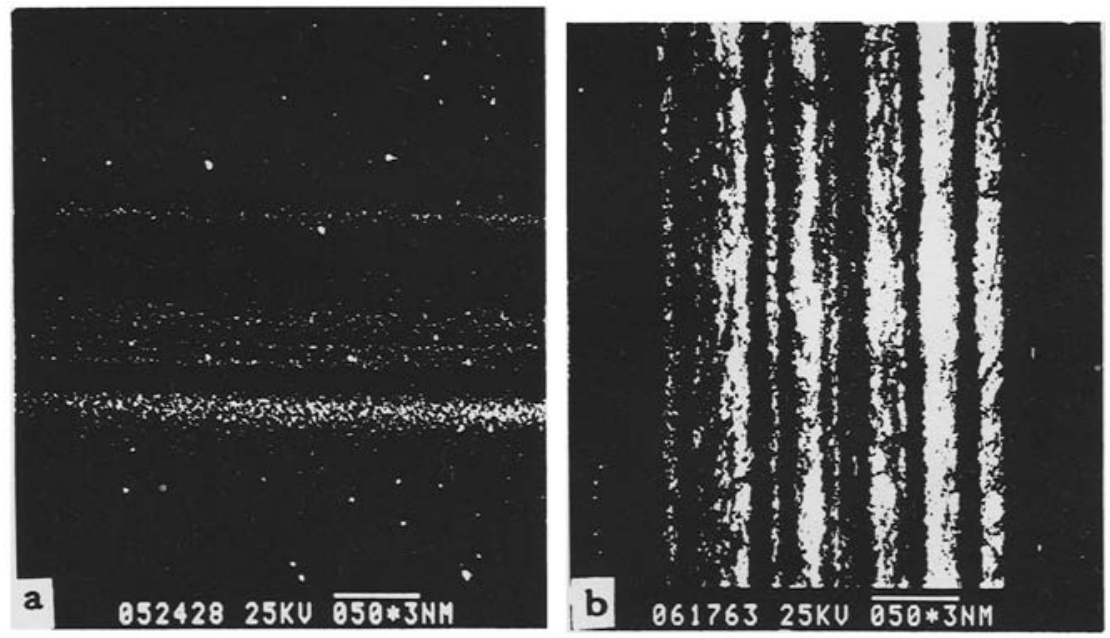

Figure 23. SEM micrographs of wear track produced by a steel ball sliding under a wear load of (a) $5 \mathrm{~N}, 70 \mathrm{~min}$; (b) $25 \mathrm{~N}, 35 \mathrm{~min}$ at $28 \% \mathrm{RH}$. 
Table 5. The wear properties of DLC films under different loads*.

\begin{tabular}{|c|c|c|c|c|c|c|c|}
\hline Load $(\mathrm{N})$ & 2 & 5 & 10 & 15 & 20 & 25 & $\begin{array}{c}5 \\
\text { uncoated }\end{array}$ \\
\hline $\begin{array}{l}\text { Sliding } \\
\text { distances }(\mathrm{m})\end{array}$ & 190 & 123 & $165 \cdot 3$ & 128.5 & 111.5 & 80 & 24 \\
\hline $\begin{array}{l}\text { Groove wear } \\
\text { volume } \\
\left(\times 10^{6} \mathrm{~mm}^{3}\right)\end{array}$ & $34 \cdot 4$ & $124 \cdot 9$ & $524 \cdot 3$ & $504 \cdot 3$ & 308.5 & 203.92 & $8781 \cdot 2$ \\
\hline $\begin{array}{l}\text { Wear coeff. } \\
\left(\mathrm{K} \times 10^{6}\right)\end{array}$ & 1.99 & 4.47 & 6.99 & $5 \cdot 76$ & 3.04 & $2 \cdot 24$ & 658.59 \\
\hline AWN & $5 \cdot 7$ & $5 \cdot 35$ & $5 \cdot 16$ & $5 \cdot 24$ & 5.52 & $5 \cdot 65$ & $3 \cdot 18$ \\
\hline
\end{tabular}

*All tests were carried out at a temperature of about $27^{\circ} \mathrm{C}$ and relative humidity of $28 \%$.

The wear properties summarized from the tribological test series are listed in table 5. It can be found that there are two features of the tribological performance of DLC film. The first is that in the wear load range of $2-25 \mathrm{~N}$, the wear coefficients of DLC films are 1.99-6.99 $\times 10^{-6}$, two orders lower than the value for uncoated disc $\left(658.59 \times 10^{-6}\right)$. The AWNs also show an average value of $5.44 \pm 0.27$, which is much larger than that of uncoated steel disc (about 3.18). Secondly, when the wear loads increase from $2 \mathrm{~N}$ to $25 \mathrm{~N}$, the values of $\mathrm{AWNs}$ do not vary greatly. These experimental data definitely illustrate that due to dynamic mixing at $\mathrm{DLC} / \mathrm{Mo} / \mathrm{Fe}$ interfaces, DLC films deposited on $\mathrm{Mo} /$ steel substrate can notably enhance the tribological performance of AISI 52100 steel, which provides a useful method to apply DLC coatings on steel parts for surface modification under high wear loads.

\section{Conclusions}

(i) A narrow energy window between 200 and $400 \mathrm{eV}$ is observed to produce the best results. Raman, XPS, and AES spectra all indicate that DLC films synthesized under $200-400 \mathrm{eV}$ ion bombardment possess valence band structure similar to that of diamond and contain more $s p^{3}$ bonds.

(ii) It is proved that DLC films with very diamond-like properties can be prepared by IBAD process at room temperature. With low-energy-assisted bombardment, DLC films can obtain a high hardness and reach $5100 \mathrm{kgf} / \mathrm{mm}^{2}$ when bombarded under $200 \mathrm{eV} \mathrm{CH}^{n+}$.

(iii) For practical purposes, DLC on 52100 was chosen for investigation. The tribological studies of DLC/52100 system have yielded very promising antiwear properties. These may allow important applications.

(iv) The interface between DLC and 52100 can be tailored by high-energy atomic mixing and also by sputtering an intermediate layer such as Mo. Improvement of interface adhesion will greatly help improve the tribological behaviour of DLC on 52100 steel. 


\section{Acknowledgements}

This work is part of the " 863 " project. The authors also wish to express their thanks to Ford-China Research and Development Func for financial support.

\section{References}

Bhattacharya R S, Wu R L C and Yust C S 1991 Nucl. Instrum. Methods B59/60 1383

Braum M 1989 Nucl. Instrum. Methods B39 544

Bundy F P et al 1955 Nature (London) 17651

Deryagin B W, Spitsyn B V, Gorodetsky A E, Bouilov L L, Klotchkov A A and Smolsyaninov A M 1976 Dokl. Akad. Nauk SSSR 231333

Kobs K, Dimigen H, Denissen C J M, Gerritsen E, Politiek J, Oechsner R, Kluge A and Ryssel H 1991 Nucl. Instrum. Methods B59/60 746

Li H D 1986 Formation of metal nitrides in surface layer by direct $N^{+}$implantation thin films, Proc. 1986 China-Japan Symp. on Thin Films, JSPS p. 77

Min Z, Li W Z, Dong M J, Cui F Z and Li H D 1992 Vacuum 43945

Miyake S and Kaneko R 1991 in Applications of diamond films and related materials (eds) Y Tzeng, M Yoshikawa, M Murakawa and A Feldman (New York: Elsevier Science)

Mizokawa Y, Miyasato T, Nakamura S, Geib K M and Wilmsen C W 1987 J. Vac. Sci. Technol. A5 2809

Moravec T J and Orent T W 1981 J. Vac. Sci. Technol. 18226

Ochsner R, Kluge A, Freg L and Ryssel H 1991 Nucl. Instrum. Methods B59/60 793

Raveh A, Martinu L, Hawthorne H M and Wertheimer M R 1993 Surf. Coat. Technol. 5845

Spitsyn B V, Bouilov L L and Derjagin B V 1988 Prog. Cryst. Growth Charact. 1779

Weissmantel C, Bewilogua K, Dietrich D, Erler H -J, Hinneberg H -J, Klose S, Nowick W and Reisse G 1980 Thin Solid Films 7219 